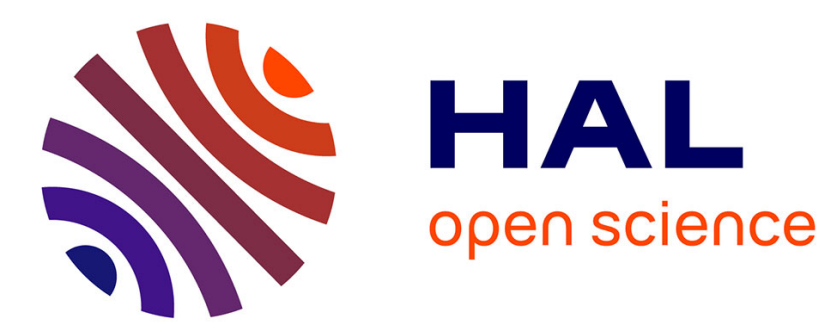

\title{
Examination of the interaction between liquid silicon and bulk silicon carbide
}

\author{
Jérôme Roger, A Marchais, Y Le Petitcorps
}

\section{To cite this version:}

Jérôme Roger, A Marchais, Y Le Petitcorps. Examination of the interaction between liquid silicon and bulk silicon carbide. Journal of Crystal Growth, 2015, 10.1016/j.jcrysgro.2015.05.013 . hal-01323669

\section{HAL Id: hal-01323669 \\ https://hal.science/hal-01323669}

Submitted on 30 May 2016

HAL is a multi-disciplinary open access archive for the deposit and dissemination of scientific research documents, whether they are published or not. The documents may come from teaching and research institutions in France or abroad, or from public or private research centers.
L'archive ouverte pluridisciplinaire HAL, est destinée au dépôt et à la diffusion de documents scientifiques de niveau recherche, publiés ou non, émanant des établissements d'enseignement et de recherche français ou étrangers, des laboratoires publics ou privés. 


\title{
Examination of the interaction between liquid silicon and bulk silicon carbide
}

\author{
J. Roger ${ }^{\mathrm{a}, *}$, A. Marchais ${ }^{\text {a }}$, Y. Le Petitcorps ${ }^{\mathrm{a}}$ \\ ${ }^{a}$ Université de Bordeaux, CNRS, Laboratoire des Composites ThermoStructuraux,
}

UMR 5801, 33600 Pessac, France

\begin{abstract}
* Corresponding author: e-mail: roger@lcts.u-bordeaux.fr, phone number: +33 5568447 36, fax number: +33556841225
\end{abstract}

\begin{abstract}
Little information is available about the evolution of $\mathrm{SiC}$ in presence of molten silicon. In this context, two kinds of experiments relative to the interaction between $\mathrm{SiC}$ substrates and molten Si were performed between 1450 and $1600^{\circ} \mathrm{C}$ with: 1) dense $\alpha$-SiC bars and 2) dense $\alpha$-SiC pellets coated with a $\beta$-SiC layer deposited by CVD. The results obtained indicate that an important crystal growth occurs in any cases. Large and facetted SiC crystals have grown on the surface of the SiC substrates and on the whole surface of molten silicon. These crystals are formed by dissolution-growth mechanism of SiC substrates with kinetics depending on the temperature. Low thermal gradients within the samples and between the inner parts and/or the surface of the samples could noticeably promote the evolution of the system by generating a carbon flux. The interaction between molten silicon and SiC is of importance because it could have some effects on the physical and chemical properties of the materials. It is well known that large grains are deleterious for mechanical properties.
\end{abstract}

\section{Keywords: A1. Diffusion; A1. Recrystallization; A2. Growth from melt; A2. Natural crystal growth; B1. Inorganic compounds; B2. Semiconducting silicon compounds;}




\section{Introduction}

$\mathrm{SiC}$ has a fairly large iconicity value of 0.177 on the Phillips scale (Garcia-Cohen 0.475 and Pauling 0.11) [1]. Nevertheless, $\mathrm{SiC}$ is generally considered as a covalent bonded compound ( $88 \%$ covalency and $12 \%$ ionic), what is sufficient in most cases to explain its chemical properties. This compound is of great importance in a broad range of technological applications because of its wide band gap, good oxidation resistance, high thermal conductivity, low density, high stiffness and adequate toughness. However, a complete understanding of the chemical behavior of this compound during the elaboration and utilization stages of the SiC-containing materials is essential. As shown on Figure 1, the Si-C system calculated with Thermocalc software contains only $\mathrm{SiC}$ as binary compound $[2,3]$. Consequently, this phase can be synthesized easily by a reaction between silicon and carbon. On this way, many studies deal about the synthesis of $\mathrm{SiC}$ by using different processes. The general idea is to promote the wetting and the reaction between molten silicon and carbon in order to form $\mathrm{SiC}$ [4-13]. The synthesis of composites materials for high temperature applications by reactive infiltration of silicon in carbon-filled preform is also a promising application of this system [14-17]. Nevertheless, according to the results in the literature, the interaction between the liquid phase and carbon is complex and not fully mastered. On a general manner, the reaction between silicon or containing-silicon alloys and carbon is known to be sudden, strongly exothermic and generally uncompleted with remaining carbon and/or free silicon $[5,6,13,18]$. The interaction between the liquid and the as-formed $\mathrm{SiC}$ is also important because it could have some effects on the properties of the so-obtained material. The effects on the microstructure of the interaction between a liquid and a ceramic were discussed by W.E. Lee et al. [19]. On this way, it was demonstrated that the presence of a low quantity of liquid during the $\mathrm{SiC}$ sintering at $1970^{\circ} \mathrm{C}$ for 6 hours is able to control the grain growth kinetic and the microstructure during the transformation of $\beta$-SiC to $\alpha-\mathrm{SiC}$ by dissolution-reprecipitation with core/rim microstructure [20]. It is worth noting that $\mathrm{SiC}$ is known under several polytypic forms [21]. Up to now, the interaction of SiC with molten 
alloys was extensively examined from the perspective of the wetting and of the reactivity in metal/ceramic couples for technological processes but there is only few information about the reactivity of pure molten silicon with $\mathrm{SiC}$ substrate [22-25]. A study on the dissolution morphology of $\mathrm{SiC}$ wafers in contact with molten $\mathrm{Fe}-\mathrm{Si}$ alloy at $1300^{\circ} \mathrm{C}$ indicates that the dissolution kinetics could be limited not only by the mass transfer but also by the interfacial reaction [26]. T. Narumi et al. also demonstrated on the basis of thermodynamic calculations that the addition of metallic elements as chromium, iron or titanium can accelerate SiC growth by increasing carbon solubility in the melt [27]. On the same way, it was reported that the contact between $\alpha$-SiC with $\mathrm{Si}_{25} \mathrm{Ge}_{75}$ melts between 1100 and $1400^{\circ} \mathrm{C}$ leads to the formation of $\beta$-SiC islands, first on the substrate and later on the carbon crucible by dissolution and transport of carbon [28]. Thus, the influence of the substrate polytype, the temperature, the heating rate and duration was demonstrated on the transformation of the $\mathrm{SiC}$ substrates. One also knows that the contact angle of pure molten silicon or of the alloys $\mathrm{Cu}-25 \%$ at.Si and $\mathrm{Ni}$ $40 \%$ at.Si on $\alpha$-SiC depends on the polar surfaces of the substrate [24]. The contact angle on the (0001)-SiC polar surface is the lowest in any cases and it is reduced by the use of an alloy which promotes adhesion. $\alpha$-SiC and $\beta$-SiC differ only from the ninth structural layer. These two kinds of $\mathrm{SiC}$ were examined because of the possible occurrence of a preferential dissolution along some crystallographic planes. Despite the high similarity of the $\alpha$ - and $\beta$ SiC polytypes, their crystallographic structures are not exactly the same, one having a cubic lattice the other one a hexagonal lattice. The $\alpha$-variety is stable at high temperature, above $2000^{\circ} \mathrm{C}$, and the $\beta$-variety is formed at lower temperatures. The chemical stabilities of these phases are a little different. The solubility and the diffusion coefficient of carbon in liquid silicon are determinant characteristics. That is why they were examined at $1600^{\circ} \mathrm{C}$ by V.N. Eremenko et al. [29]. Some others authors examined also the solubility of carbon in molten silicon $[3,30-33]$. It is clear that carbon is very slightly soluble in molten silicon at $1450^{\circ} \mathrm{C}$ (less than 100 ppm in mass) but all the studies indicate a noticeable increase with temperature (Fig. 2). The aim of the present work is to obtain more details about the dissolution and 
growth phenomena of $\mathrm{SiC}$ in molten silicon between 1450 and $1600^{\circ} \mathrm{C}$. In this aim, experiments have been done to identify the reaction mechanisms and the conditions promoting the reaction. Two kinds of substrate were examined: $\alpha$-SiC with large grains and $3 \%$ of porosity and dense $\beta-\mathrm{SiC}$ with smaller grains.

\section{Materials and experimental procedures}

The Si powder (99.995 wt.\% Si, grade AX-20, Starck, Germany) used in these experiments has a mean particle size of $7.5 \mu \mathrm{m}$. Bulk SiC was purchased to Boostec Company, France, it is composed of dense $\alpha-\mathrm{SiC}$ obtained by sintering at $2000^{\circ} \mathrm{C}$ with a low residual porosity less than $3 \%$ with a mean grain size of $5 \mu \mathrm{m}$. The interaction between massive $\mathrm{SiC}$ and molten $\mathrm{Si}$ were examined via a set of four experiments at 1450 and $1600^{\circ} \mathrm{C}$ for duration of 4 hours in alumina crucibles $\left(\varnothing 15 \times 30 \mathrm{~mm}^{3}\right)$ coated with pure micronic boron nitride $(\mathrm{BN})$ deposited from a suspension which is used as a protective layer (Fig. 3). Indeed, the $\mathrm{BN}$ coating has the advantages of being non-reactive and poorly wettable with respect to the molten silicon, thereby preventing the reaction between the molten silicon and the crucible. The smallness of the samples was chosen to minimize the thermal gradients that are estimated to be lower than $3^{\circ} \mathrm{C}$. In a first case, two bars of bulk $\operatorname{SiC}\left(5 \times 5 \times 25 \mathrm{~mm}^{3}\right)$, with surface polished down to $1 \mu \mathrm{m}$, were each placed in crucibles with $5 \mathrm{~g}$ of Si powder and heated at 1450 for one and $1600^{\circ} \mathrm{C}$ for the other one. In the second case, two pellets of dense $\operatorname{SiC}\left(\varnothing 8 \times 3 \mathrm{~mm}^{3}\right)$ coated by a $\beta$-SiC layer with a mean thickness estimated to $6.50 \mu \mathrm{m}$ and a mean grain size of about $1 \mu \mathrm{m}$ were also placed at the bottom of the crucibles in contact with the BN coating and heated with $5 \mathrm{~g}$ of Si powder at 1450 for one and $1600^{\circ} \mathrm{C}$ for the other one. The $\beta$-SiC layer was obtained by Chemical Vapor Deposition (CVD) at $1000^{\circ} \mathrm{C}$ from a mixture made of methyltrichlorosilane and dihydrogen [34]. In all cases, the heating was performed in an inductively heated graphite susceptor in presence of hafnium powder as oxygen getter. During the temperature increase, a deoxidization step of the materials was made by maintaining the temperature at $1395^{\circ} \mathrm{C}$, 
below the melting point of silicon, during 1 hour under a dynamic vacuum with a pressure of $5.10^{-7}$ bar. Then, a continuous flow of high purity argon under normal pressure was applied to prevent silicon vaporization and oxygen pollution. After heating, the samples were cut in order to examine the interaction surfaces between the bulk $\mathrm{SiC}$ and the liquid. The micrographic observations were performed with a FEI Quanta 400 FEG scanning electron microscope, and the chemical compositions were analyzed by EDX (EDAX Genesis XM4), operated at $10 \mathrm{kV}$.

\section{Results}

According to the Si-C phase diagram, $\mathrm{SiC}$ and carbon-free molten silicon are not in equilibrium (Fig. 1). The first interaction that occurs is the carbon saturation of the liquid by dissolution of $\mathrm{SiC}$. The solubility of carbon in molten silicon between 1450 and $1600^{\circ} \mathrm{C}$ being low (Fig. 2), a much reduced quantity of $\mathrm{SiC}$ is dissolved to saturate the liquid. The mass of $\mathrm{SiC}$ decomposed to saturate $5 \mathrm{~g}$ of pure silicon at $1600^{\circ} \mathrm{C}$ is estimated to be about $1.10^{-3} \mathrm{~g}$. So, it could be considered as negligible.

\subsection{Interaction between molten silicon and the atmosphere of the furnace}

Prior to the examination of the SiC-Si interaction, the melt of $5 \mathrm{~g}$ of pure silicon was realized at $1600^{\circ} \mathrm{C}$ for 4 hours in alumina crucible coated with BN. One can see on the Figure 4 that a continuous layer of $\mathrm{SiC}$ crystals with a thickness between 25 and $50 \mu \mathrm{m}$ has been formed on the surface of the melted silicon with some protuberances enriched in $\mathrm{SiC}$ crystals. It can be deduced that during the heating, the atmosphere of the furnace contains traces of molecules promoting the transportation of carbon from the graphite susceptor. This leads to the nucleation and growth of SiC crystals at the triple point of the system which is the surface of 
the melt in the present case. The so-obtained SiC layer can generate a passivation effect with a very low later evolution of the layer.

\subsection{Interaction between SiC bars and molten silicon}

The first set of two samples examined was composed of a bar of sintered $\alpha$-SiC partially surrounded by $5 \mathrm{~g}$ of silicon, as represented on the Figure 3-a. After the heating at 1450 or $1600^{\circ} \mathrm{C}$, the samples exhibit significant differences as shown on the Figures 5 and 6 . In both cases, $\mathrm{SiC}$ crystals are formed at the surface of the melt, a stronger quantity is obtained at $1600^{\circ} \mathrm{C}$ (Fig. 5-a, Fig. 6-b). As showed on the Figure 5-b, large crystals of SiC are formed at $1450^{\circ} \mathrm{C}$ on one corner of the bar. A closed examination of the SiC-Si interfaces (Fig.5-c) brings to the light that the sizes of the crystals are comprised between 10 to $100 \mu \mathrm{m}$ and most of them are smaller than $50 \mu \mathrm{m}$ and grew from the surface of the SiC substrate. The bigger ones, larger than $50 \mu \mathrm{m}$, are close to the substrate surface but generally without bonding. The other side of this sample is crystal-free and seems to have been locally attacked and weakened by the liquid (Fig. 5-d). The situation is a little different with the $\mathrm{SiC}$ bar heated at $1600^{\circ} \mathrm{C}$ (Fig. 6). Indeed, the SiC layer at the surface of the melt is continuous and thicker, what could be attributed to the higher temperature. One can also observe that the liquid covers a large part of the $\mathrm{SiC}$ bar and wets the top of the sample; this was not the case for the sample heated at $1450^{\circ} \mathrm{C}$. The liquid which covers the not-immersed surfaces contains a great quantity of $\mathrm{SiC}$ crystals forming some kind of parallel layers along the surface of the substrate (Fig. 6-a). On the upper part of the immerge surfaces, a continuous and free layer made of large SiC crystals was formed (Fig. 6-b). On the bottom part of the substrate, only few small crystals grew locally without forming a continuous layer (Fig. 6-c,d). From these results it can be deduced that two phenomenon occur during the heating leading both to the growth of large $\mathrm{SiC}$ crystals. At relative low temperature i.e. $1450^{\circ} \mathrm{C}$, a dissolution-growth process occurs but it is controlled by a thermal gradient through the sample. The estimation of the dissolution rate of 
the $\mathrm{SiC}$ was difficult to realize because it was needed to keep intact a part of the starting surface of the substrate close to the melt. Measurement attempts were not significant due to insufficient thickness variations. The dissolution area is believed to be elevated compared to the area of growth, so that the quantity of $\mathrm{SiC}$ dissolved is too few to be precisely measured. Indeed, as schematically represented on the Figure 7, the bottom of the sample (crucible, SiC bar and molten silicon) is in contact with the susceptor and its top part is in direct contact with the Ar atmosphere of the furnace inducing a cooling effect. As a consequence, the dissolution occurs on the whole surface of the substrate but in a more consequent proportion at the hotter side. The large SiC crystals are then formed at the colder side. The tilt of the sample heat treated at $1450^{\circ} \mathrm{C}$ leads to the growth of the $\mathrm{SiC}$ crystals on one side of the bar, the most cooled by the gas flow, detrimentally to the other side. At $1600^{\circ} \mathrm{C}$, the crystal growth is promoted and it is believed that a continuous layer of large SiC crystals was formed and grew on the colder surfaces of the bar. When a given size of the layer is reached, it becomes unstable and come apart from the substrate (Fig. 6-b). This is induced by the growth of a layer that occurs only from some crystals at the surface of the substrate, as shown on Figure 5-c. Attentively watching Figure 6-a, it can be observed than the layer at the surface of the substrate is not adherent and is about to breaking away. This instability is induced by the growth of $\mathrm{SiC}$ crystals between the layer and the substrate and maybe also by the partial dissolution of the substrate. It must be specified for more comprehension that the corresponding sample being less tilted, the colder surfaces were located symmetrically along the bar so that the growth of the SiC crystals occurs on the whole upper side of the bar detrimentally to the lower side. This behavior tends to suggest that the $\mathrm{SiC}$ layers grow from the colder surface of the substrate up to become free. The liquid that wets the non-immersed surfaces of the sample (Fig. 6-a) exhibits a clear sequence of successive SiC layers which could be promoted by carbon supply by the atmosphere, the exchange being facilitated by a relative large surface of exchange. It should be noticed that if the formation of SiC crystals was only induced by the carbon from the furnace atmosphere, the formed layer should be 
more adherent on the substrate. This property is the basis of the epitaxial or heteroepitaxial growth of $\mathrm{SiC}$ layers by Vapor-Liquid-Solid (VLS) mechanism [35-37]. This process probably occurs but it is not believed to be dominant.

\subsection{Interaction between SiC pellets coated with $\beta-C V D$ SiC and molten silicon}

The second kind of samples used in this work is made of dense $\alpha-S i C$ pellets coated by a $\beta$ SiC layer (Fig. 8, 9). These pellets were placed in contact with molten silicon in order to cover the whole surface. This configuration is different from the previous samples by the facts that the $\mathrm{SiC}$ at the surface is $\beta-\mathrm{SiC}$ and that the samples are smaller. In the case of the sample heated at $1450^{\circ} \mathrm{C}$ for 4 hours, large crystals of about $50 \mu \mathrm{m}$ grow on a large part of the pellet surface (Fig. 8-b). The $\beta$-SiC coat close to the large SiC crystals was found similar or a little reduced (Fig. 8-c), the mean thickness on 20 measures being estimated equal to $6.30 \mu \mathrm{m}$ comparing to the initial thickness of $6.50 \mu \mathrm{m}$. But some others surfaces were crystals-free and the $\beta$-SiC layer was found sensibly more attacked with an average thickness estimated on 20 measures equal to $6.10 \mu \mathrm{m}$ (Fig. 8-d). So, the thickness loss is weak depending on the considered area. Nevertheless, this lost of matter seems sufficient to generate some thick crystals on one side of the sample. Once again, the influence of thermal gradient through the sample could induce a preferential area of growth of the crystals detrimentally to the hottest part of the surface. For the sample heated at $1600^{\circ} \mathrm{C}$, it was found that the whole surface of the melt is covered by a continuous $\mathrm{SiC}$ layer. The quantity of SiC crystal formed at the top of the Si melt, above the pellet, is also higher and generate some large protuberances as show on the Figure 9-a. The formation of some crystals is also observed at the top and on the sides of the pellet (Fig. 9-b,c). An infiltration of liquid inside the pellet also occurs but only on the upper part (Fig. 9-b). Moreover, the surface of the $\mathrm{SiC}$ pellet is strongly attacked with the total dissolution of the $\mathrm{SiC}$ layer formed by CVD. The decomposition of the $\mathrm{SiC}$ layer is still in progress at the bottom of the pellet close to the interface between the liquid and the area 
protected by the BN coating (Fig. 9-d). From these results, the dissolution of $\mathrm{SiC}$ is found very important on the whole surface in contact with molten silicon up to destroy the $\beta$-SiC layer. It is worth noting that only few isolated crystals were found into the melt of silicon. One can consider that at least two stages occurred; the first one is the dissolution-growth of $\mathrm{SiC}$ close to the surface of the pellet. The second stage is the growth of many crystals at the surface of the melt to the detriment of the crystals grown at the surface of the pellet. This last fact is induced by the thermal gradient through the melt cooled by the argon flow, the upper part being colder than the lower one.

\section{Discussion}

The Figure 7 summarizes schematically the results obtained after the heating of the SiC bulk samples at 1450 and $1600^{\circ} \mathrm{C}$ during 4 hours. All the observations demonstrated that a noticeable interaction occurs between dense $\mathrm{SiC}$ and molten silicon. A mechanism is proposed on the Figure 10. In a first stage, a $(\mathrm{Si}, \mathrm{C})$ liquid saturated in carbon is formed by the dissolution of a small amount of dense $\mathrm{SiC}$ and/or by the supply of carbon from the furnace atmosphere. Then, the dissolution-growth occurs first by the dissolution of $\mathrm{SiC}$ in the liquid mainly on the hottest surface of the substrate with the growth of some favorable crystals on the coldest side by carbon transportation through the liquid. But, the precipitation and growth of large crystals occur also at the top surface of the melt by carbon transportation from the graphite susceptor. The development of these $\mathrm{SiC}$ crystals can form a continuous layer at the surface of the melt generating a new and colder substrate which interferes with the dissolution-growth of $\mathrm{SiC}$ crystals at the surface of the substrate by catching more and more carbon from the substrate and from the grown crystals. The competition between the different areas depends on their temperature and consequently on their carbon solubility. Indeed, the hottest liquid areas having higher carbon solubilities, the chemical homogenization of the liquid by diffusion of carbon enriches the coldest areas up to supersaturation inducing the growth of the closest crystals. This mechanism provokes the dissolution of the large $\mathrm{SiC}$ 
crystals formed at the surface of the SiC substrate for supplying the crystals layer at the top of the melt. This can explain the observations exposed herein with the dissolution of the substrate, the local formation and decomposition of larger SiC crystals close to the substrate and the development of a layer at the top of the melt. The driving force of the dissolutiongrowth of $\mathrm{SiC}$ crystals is a small thermal gradient inducing the dissolution of $\mathrm{SiC}$ on the hotter area to saturate the liquid, the diffusion of carbon along the thermal gradient and the growth of the $\mathrm{SiC}$ crystal in the colder area. No influence of the nature of the SiC substrate has been identified.

\section{Conclusion}

From these experimental results, the interaction between $\mathrm{SiC}$ and molten silicon appears to be strongly dependent on the temperature and on the thermal gradients. A coherent mechanism with two main stages is proposed according to the results of the experiments with dense $\mathrm{SiC}$ substrates. The molten $\mathrm{C}$-saturated silicon induces a dissolution-growth of $\mathrm{SiC}$ crystals. The growth occurs mainly on the SiC coldest surfaces of the sample by dissolution of the hottest $\mathrm{SiC}$ areas. In order to homogenize the chemical composition, the carbon in solution diffuses along its chemical gradient, corresponding to the thermal gradient. The solubility of carbon in molten silicon decreasing with temperature, the liquid in colder areas is then supersaturated, what is responsible for the growth of large $\mathrm{SiC}$ crystals at the coldest areas. Two successive areas of growth have been identified: the surface of the starting $\mathrm{SiC}$ substrate and the $\mathrm{SiC}$ layer formed at the surface of the melt. The crystal growth of $\mathrm{SiC}$ in presence of molten silicon appears to be a substantial and complex phenomenon whose driving-force is the thermal gradient that could be very low. It would be better to take it into account in all processes bringing together these two phases because it could influence the overall evolution of the system and consequently the resulting properties. One of the actual challenges is to model such a chemical system by considering the thermal, thermodynamic and kinetic 
phenomena that occur between a ceramic and a liquid. On this way this study gives some relevant results about the SiC-molten $\mathrm{Si}$ system.

\section{Acknowledgement}

This work has been performed within the frame of the training of J. Poinsot from PHELMA Grenoble. 


\section{References}

[1] Group IV Elements, IV-IV and III-V Compounds. Part B - Electronic, Transport, Optical and Other Properties Landolt-Börnstein - Group III Condensed Matter Volume 41A1b, 2002.

[2] J. Andersson, T. Helander, L. Höglund, P. Shi, B. Sundman, Thermo-Calc and Dictra, Calphad (26) (2002) 273-312.

[3] J. Grobner, H.L. Lukas, F. Aldinger, Thermodynamic calculation of the ternary system AlSi-C, Calphad 20(2) (1996) 247-254.

[4] R. W. Bartlett, W. E. Nelson, F. A. Halden, Influence of carbon transport kinetics on solution growth of 3-silicon carbide crystals, J. Electrochem. Soc. 11 (1967) 1149-1154.

[5] R. Pampuch, E. Walasek, J. Bialoskbrski, Reaction mechanism in carbon-liquid silicon systems at elevated temperatures, Ceram. Inter. 12 (1986) 99-106.

[6] R. Pampuch, J. Bialoskbrski, E. Walasek, Mechanism of reactions in the $\mathrm{Si}_{1}+\mathrm{C}_{\mathrm{f}}$ system and the self-propagating high-temperature synthesis of silicon carbide, Ceram. Inter. 13 (1987) 63-68.

[7] R. Deike, K. Schwerdlfeger, Reactions between liquid silicon and different refractory materials, J. Electrochem. Soc. 142(2) (1995) 609-614.

[8] H. Zhou, R.N. Singh, Kinetics model for the growth of silicon carbide by reaction of liquid silicon with carbon, J. Am. Ceram. Soc. 78(9) (1995) 2456-2462.

[9] J.G. Li, H. Hausner, Reactive wetting in the liquid-silicon/solid-carbon system, J. Am. Ceram. Soc. 79(4) (1996) 873-880.

[10] O. Chakrabarti, P. Kumar Das, Reactive infiltration of Si-Mo alloyed melt into carbonaceous preforms of silicon carbide, J. Am. Ceram. Soc. 83(6) (2000) 1548-1550.

[11] A. Favre, H. Fuzellier, J. Suptil, An original way to investigate the siliconizing of carbon materials, Ceram. Inter. 29 (2003) 235-243. 
[12] V. Bougiouri, R. Voytovych, N. Rojo-Calderon, J. Narciso, N. Eustathopoulos, The role of the chemical reaction in the infiltration of porous carbon by NiSi alloys, Scr. Mater. 54 (2006) 1875-1878.

[13] J.C. Margiotta, D. Zhang, D.C. Nagle, C.E. Feeser, Formation of dense silicon carbide by liquid silicon infiltration of carbon with engineered structure, J. Mater. Res. 23(5) (2008) $1237-1248$

[14] P. Sangsuwan, S.N. Tewari, J.E. Gatica, M. Singh, R. Dickerson, Metall. Mater. Trans. B 30 (1999) 933-944.

[15] Y. Pan, J.L. Baptista, Spontaneous infiltration of iron silicides into silicon carbide powder preforms, J. Am. Ceram. Soc. 83(12) (2000) 2919-2924.

[16] Y. Wang, S. Tan, D. Jiang, The effect of porous carbon preform and the infiltration process on the properties of reaction-formed SiC, Carbon 42 (2004) 1833-1839.

[17] W.B. Tian, H. Kita, H. Hyuga, N. Kondo, Synthesis, microstructure and mechanical properties of reaction-infiltrated $\mathrm{TiB}_{2}-\mathrm{SiC}-\mathrm{Si}$ composites, J. Alloys Compd. 509 (2011) $1819-1823$

[18] R. Voytovych, R. Israel, N. Calderon, F. Hodaj, N. Eustatopoulos, Reactivity between liquid Si or Si alloys and graphite, J. Eur. Ceram Soc. 32 (2012) 3825-3835.

[19] W.E. Lee, D.D. Jayaseelan, S. Zhang, Solid-liquid interactions: The key to microstructural evolution in ceramics, J. Eur. Ceram. Soc. 28 (2008) 1517-1525.

[20] M. Keppeler, H.G. Reichert, J. M. Broadley, G. Thurn, I. Wiedmann, F. Aldinger, High temperature mechanical behaviour of liquid phase sintered silicon carbide, J. Eur. Ceram. Soc. 18 (1998) 521-526.

[21] P.T.B. Shaffer, A Review of the structure of silicon carbide, Acta Cryst. B25 (1969) 477488.

[22] K. Nogi, K. Ogino, Wettability by liquid pure metals, Trans. Japan Inst. Met. 29(9) (1988) 742-747. 
[23] C. Rado, S. Kalogeropoulou, N. Eustathopoulos, Wetting and adhesion in metal-silicon carbide systems: the effect of surface polarity of SiC, Scr. Mater. 42 (2000) 203-208.

[24] C. Rado, B. Drevet, N. Eustathopoulos, The role of compound formation in reactive wetting: the $\mathrm{Cu} / \mathrm{SiC}$ system, Acta Mater. 48 (2000) 4483-4491.

[25] G.W. Liu, M.L. Muolo, F. Valenza, A. Passerone, Review survey on wetting of SiC by molten metals, Ceram. Inter. 36 (2010) 1177-1188.

[26] S. Kawanishi, T. Yoshikawa, K. Morita, K. Kusunoki, K. Kamei, H. Suzuki, H. Sakamoto, Real-time observation of the interface between $\mathrm{SiC}$ and a liquid alloy and its application to the dissolution behavior of $\mathrm{SiC}$ at 1573K, J. Appl. Phys. 114 (2013) 214313.

[27] T. Narumi, S. Kawanishi, T. Yoshikawa, K. Kusunoki, K. Kamei, H. Daikoku, H.Sakamoto, Thermodynamic evaluation of the $\mathrm{C}-\mathrm{Cr}-\mathrm{Si}, \mathrm{C}-\mathrm{Ti}-\mathrm{Si}$, and $\mathrm{C}-\mathrm{Fe}-\mathrm{Si}$ systems for rapid solution growth of SiC, J. Crys. Growth 408 (2014) 25-31.

[28] O. Kim-Hak, G. Ferro, J. Lorenzzi, D. Carole, J. Dazord, P. Chaudouët, D. Chaussende, P. Miele, Evolution of 3C-SiC islands nucleated from a liquid phase on Si face $\alpha$-SiC substrates, Thin Solid Films 518 (2010) 4234-4241.

[29] V.N. Eremenko, G. Gnesin, M.M. Churakov, Dissolution of polycrystalline silicon in liquid silicon, Poroshkovaya Metall. 6(114) (1972) 55-59.

[30] K. Yanaba, M. Akasaka, M. Takeuchi, M. Watanabe, T. Narushima, Y. Igushi, Solubility of carbon in liquid silicon equilibrated with silicon carbide, Mater. Trans. 38(11) (1997) 990-994.

[31] R.N. Hall, Electrical contacts to silicon carbide, J. Appl. Phys. 29 (1958) 914-917.

[32] R. I. Scace, G. A. Slack, Solubility of carbon in silicon and germanium, J. Chem. Phys. 30 (1959) 1551-1555.

[33] H. Dalaker, M. Tangstad, Time and temperature dependence of the solubility of carbon in liquid silicon equilibrated with silicon carbide and its dependence on boron levels, Mater. Trans. 50(5) (2009) 1152-1156. 
[34] F. Loumagne, F. Langlais, R. Naslain, Reactional mechanisms of the chemical vapour deposition of SiC-based ceramics from $\mathrm{CH}_{3} \mathrm{SiCl}_{3} / \mathrm{H}_{2}$ gas precursor, J. Cryst. Growth 155 (1995) 205-213

[35] K. Kusunoki, K. Kamei, N. Yashiro, T. Tanaka, A. Yauchi, Solution growth and crystallinity characterization of bulk 6H-SiC, Mater. Sci. Forum 600-603 (2009) 187-190.

[36] A. Tanaka, N. Shiozaki, H. Katsuno, Synthesis and growth of 3C-SiC crystals from solution at $950^{\circ} \mathrm{C}$, J. Cryst. Growth 237-239 (2002) 1202-1205.

[37] M. Soueidan, G. Ferro, O. Kim-Hak, F. Robaut, O. Dezellus, J. Dazord, F. Cauwet, J.C. Viala, Nucleation of 3C-SiC on 6H-SiC from a liquid phase, Acta Mater. 55 (2007) 68736880. 


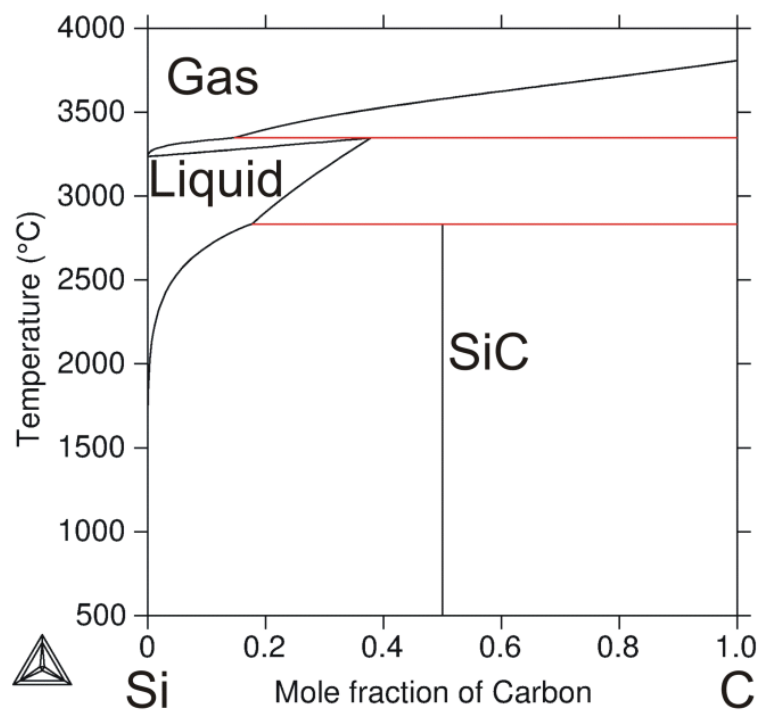

Figure 1. Calculated Si-C diagram [2,3].

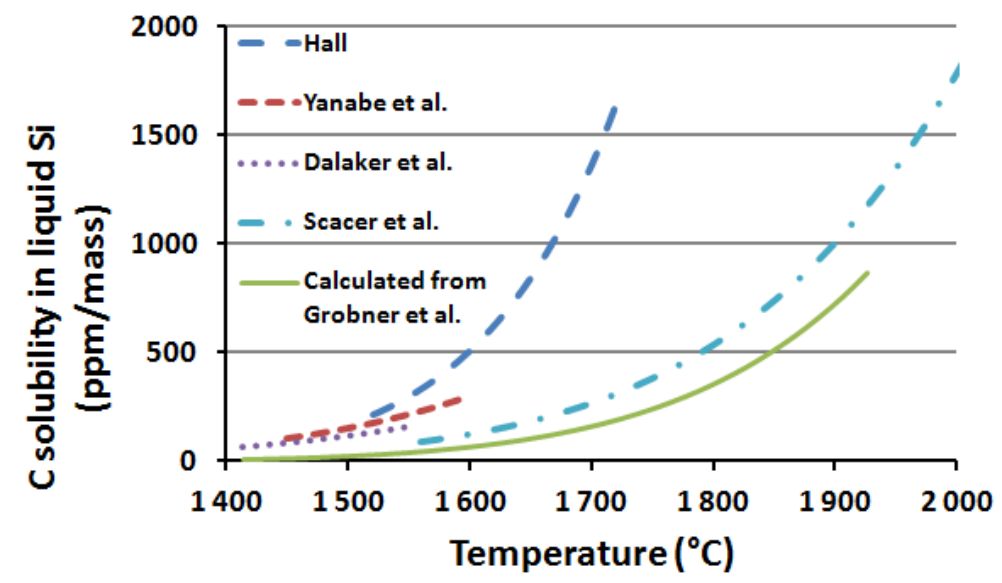

Figure 2. Solubility of carbon in molten silicon from literature [3, 30-

33]. The values from Grobner et al. were calculated by using ThermoCalc software [2].

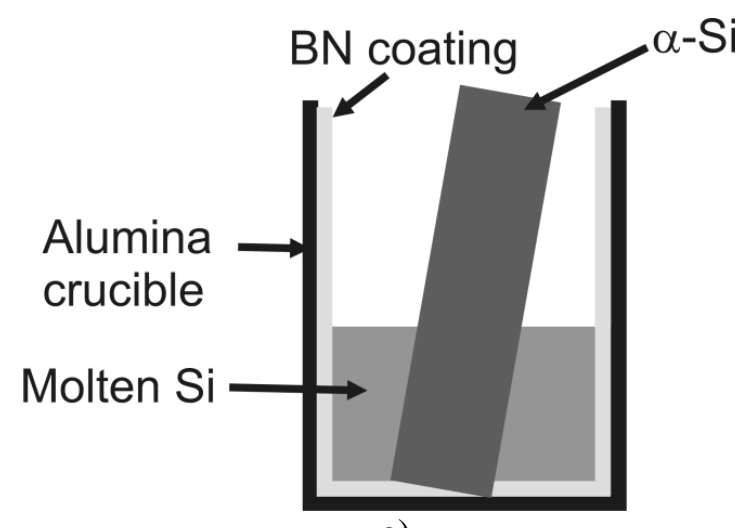

a)

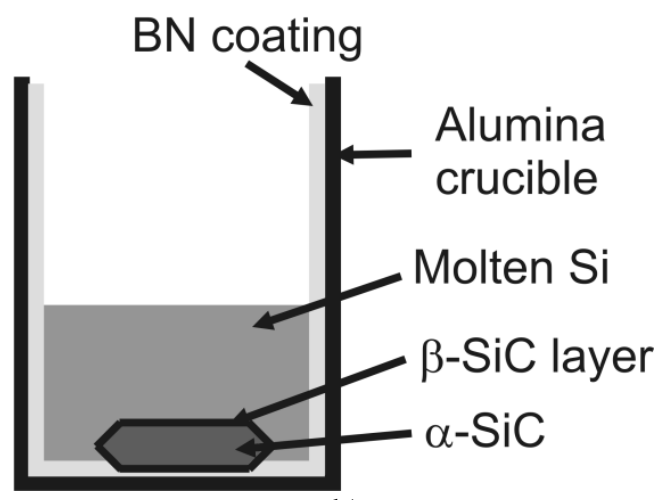

b)

Figure 3. Schematic representations of the two different kinds of samples during a heat treatment at 1 or $1600^{\circ} \mathrm{C}$ in molten $\mathrm{Si}$ : a) $\alpha$-SiC bar and b) $\alpha$-SiC pellet with a coating of $\beta$-SiC 


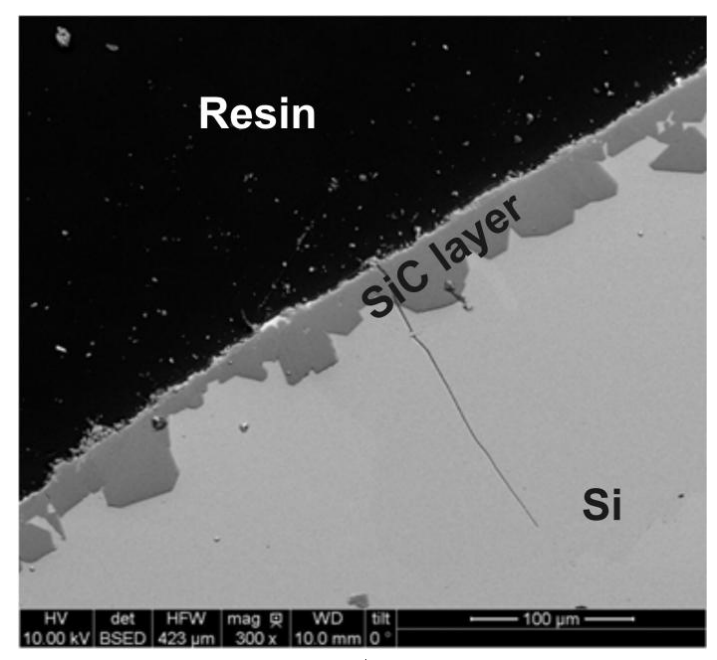

a)

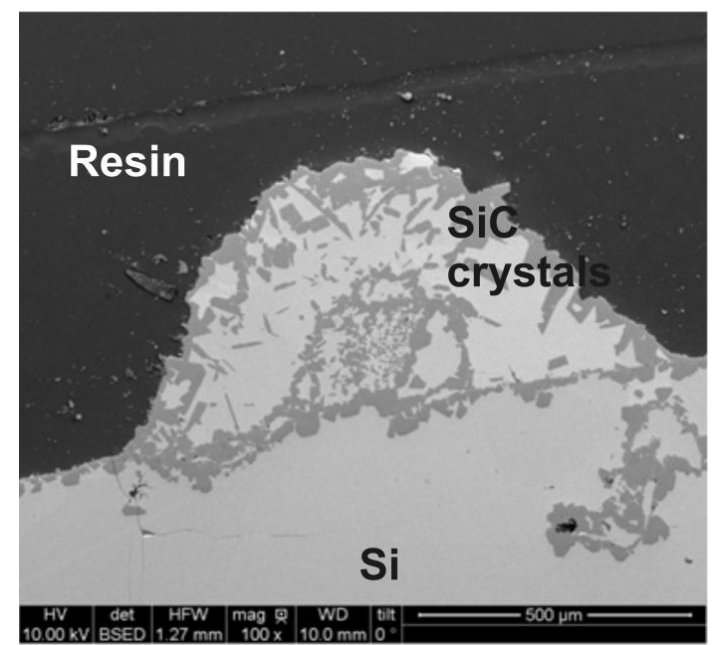

b)

Figure 4. Backscattered electrons images of pure silicon after $1600^{\circ} \mathrm{C}$ for $4 \mathrm{~h}$ :

a) $\mathrm{SiC}$ layer at the surface, b) $\mathrm{Si}-\mathrm{SiC}$ protuberance at the top.

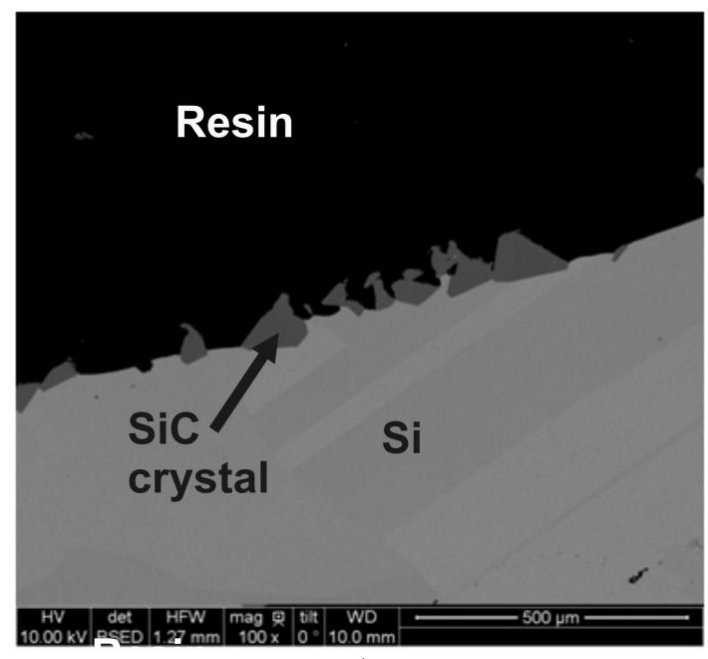

a)

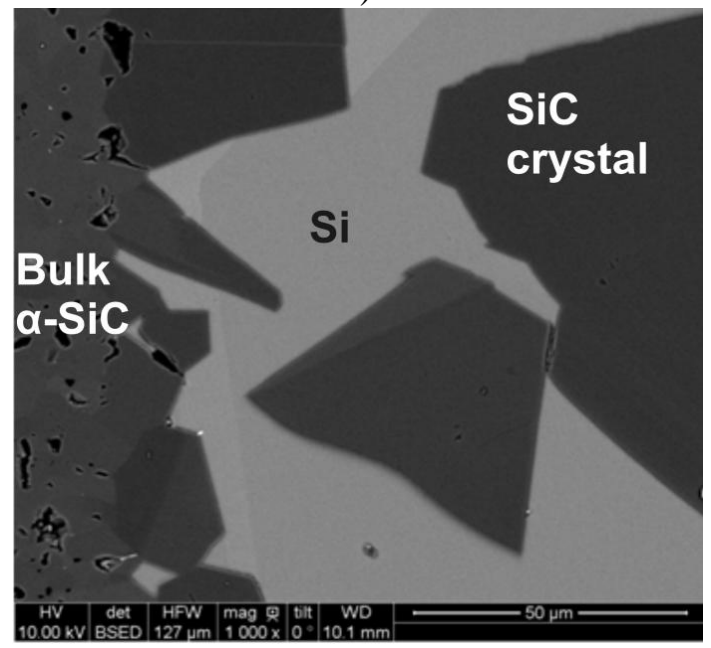

c)

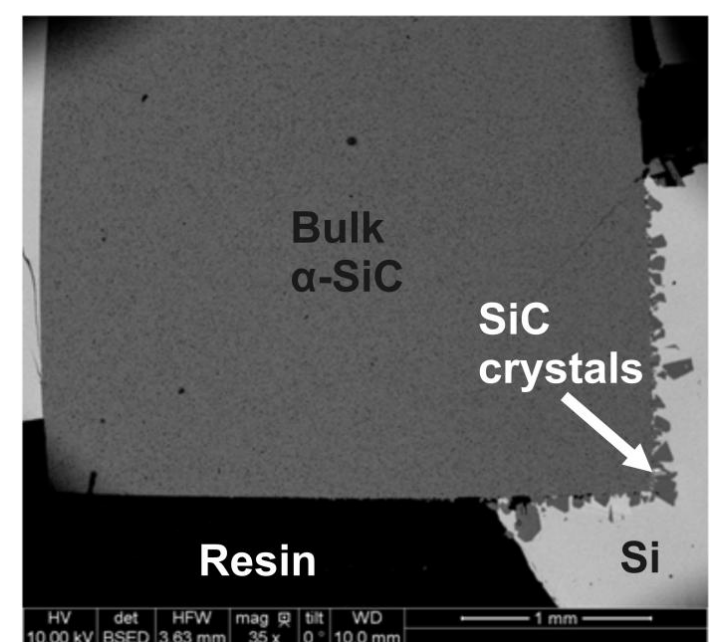

b)

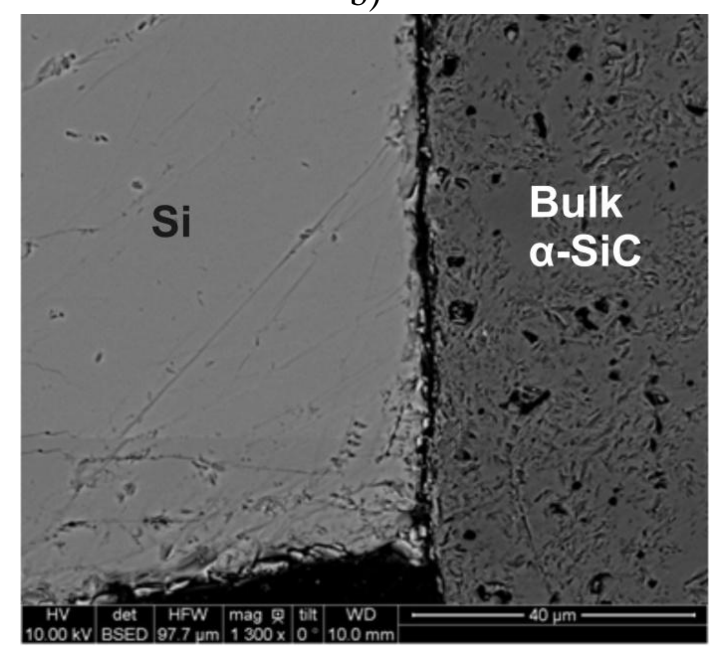

d)

Figure 5. Backscattered electrons images of the $\mathrm{SiC}$ bar in silicon after $1450^{\circ} \mathrm{C}$ for $4 \mathrm{~h}$ :

a) at the top of the Si melt, b) overall view of bottom of the sample,

c) at the interface $\mathrm{SiC} / \mathrm{Si}$ on the left side, d) at the interface $\mathrm{SiC} / \mathrm{Si}$ on the right side. 


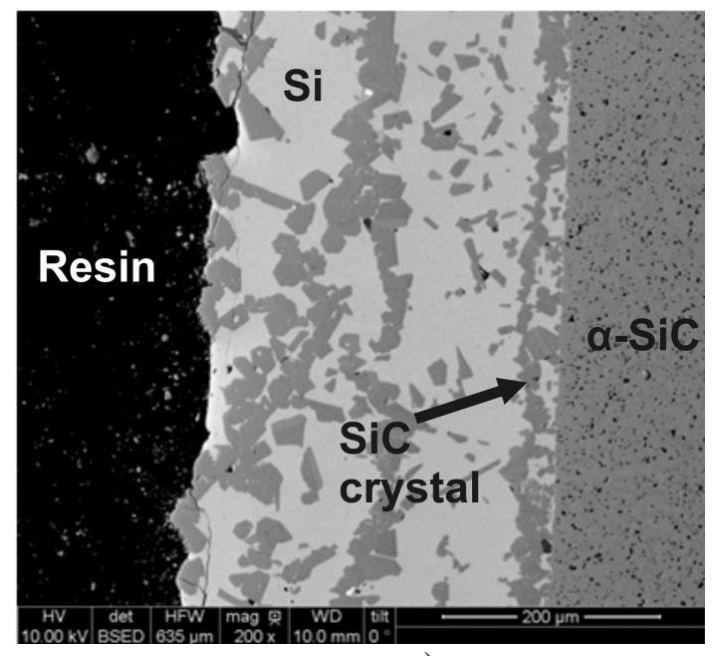

a)

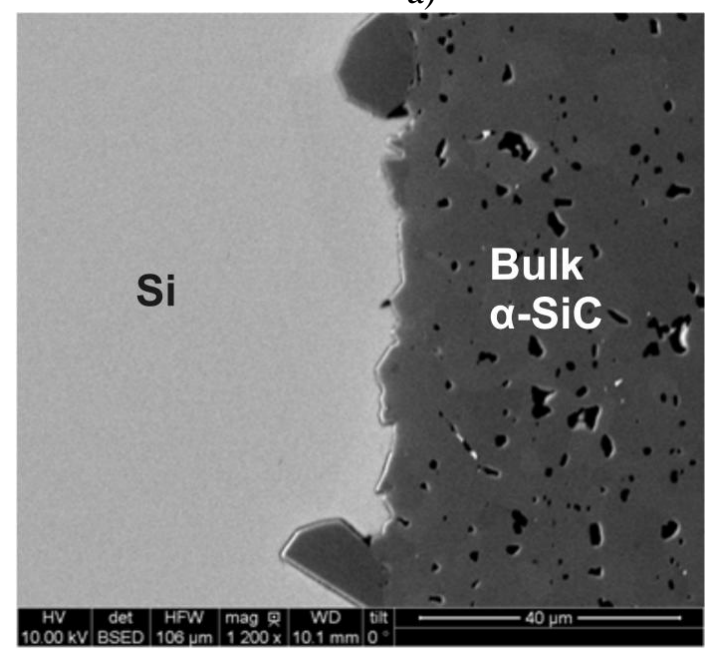

c)

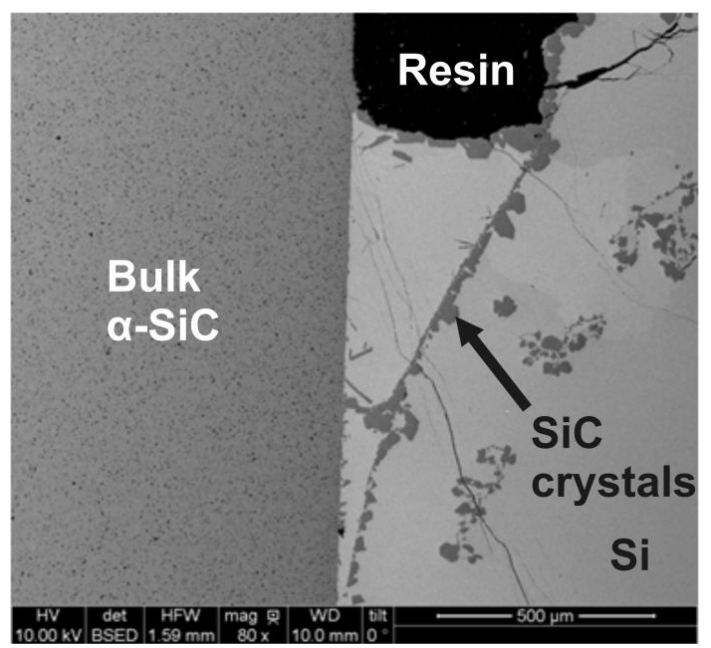

b)

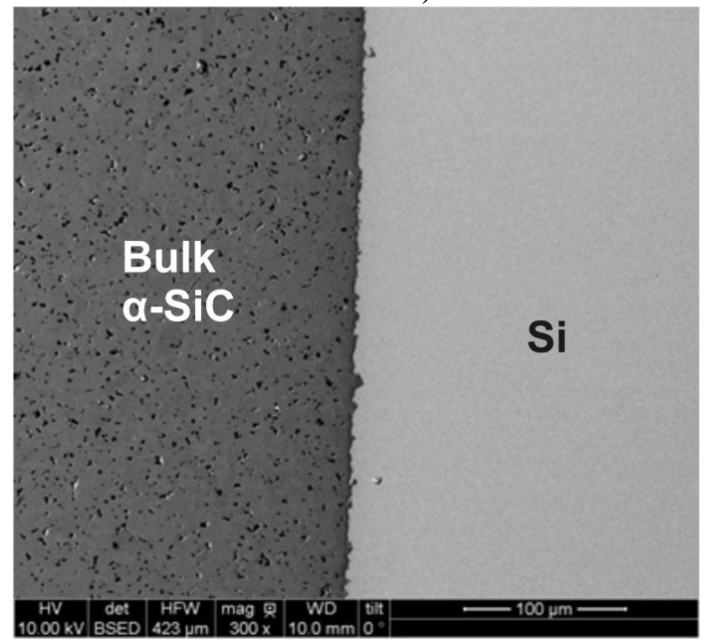

d)

Figure 6. Backscattered electron images of the $\mathrm{SiC}$ bar in silicon after $1600^{\circ} \mathrm{C}$ for $4 \mathrm{~h}$ :

a) at the surface of the non-immersed part, b) at the top of the immersed part,

c) at the left bottom of the immersed part, d) at the right bottom of the immersed part.
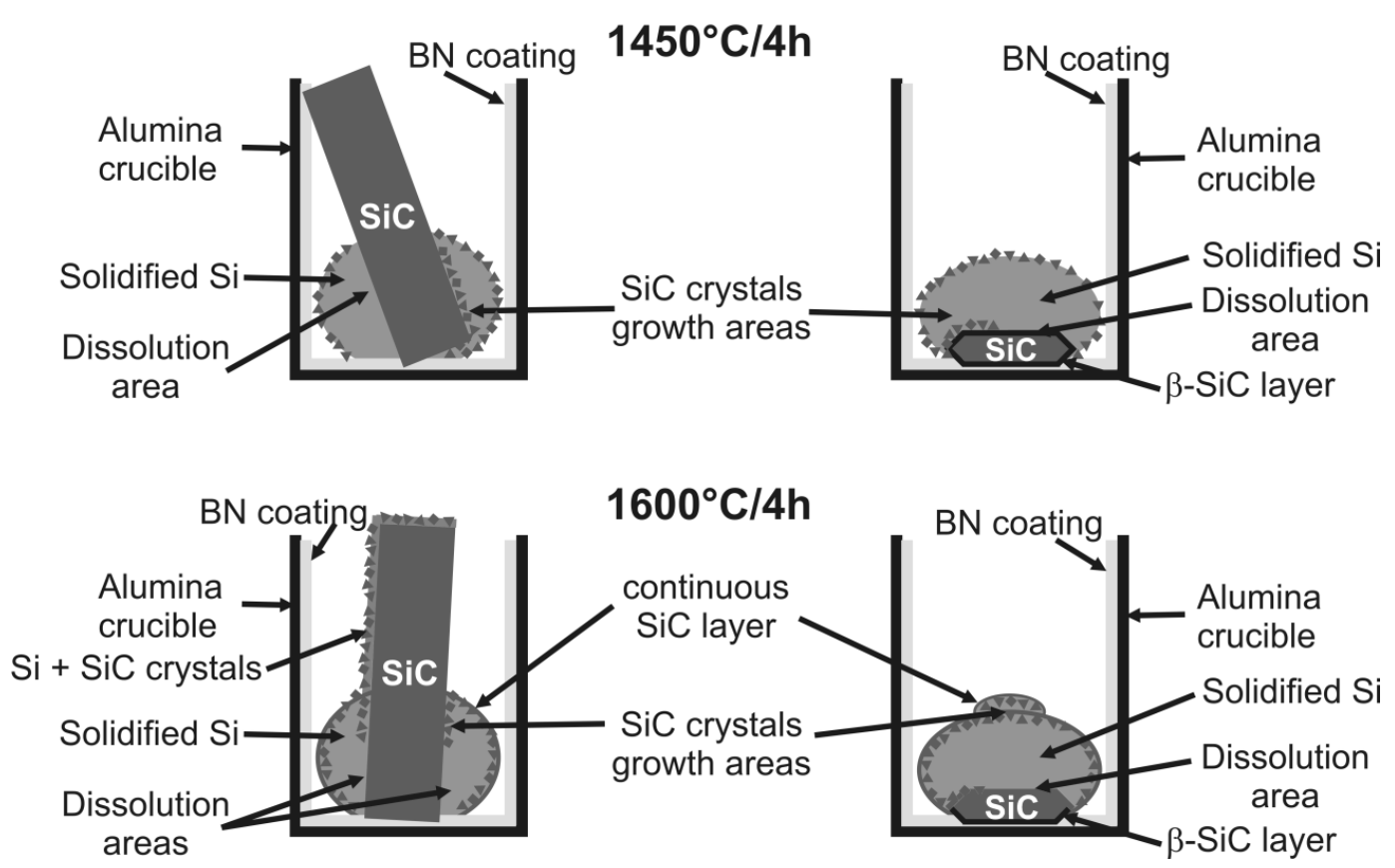

Figure 7. Schematic representations of the $\mathrm{SiC}$ dense samples after heating at 1450 or $1600^{\circ} \mathrm{C}$

for 4 hours. $\mathrm{SiC}$ bars samples are on the left side and the $\mathrm{SiC}$ pellets on the right side. 


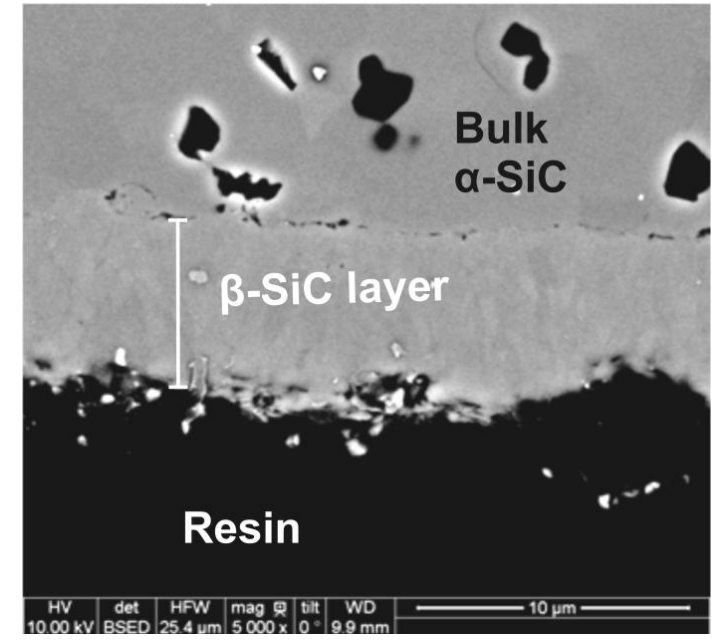

a)

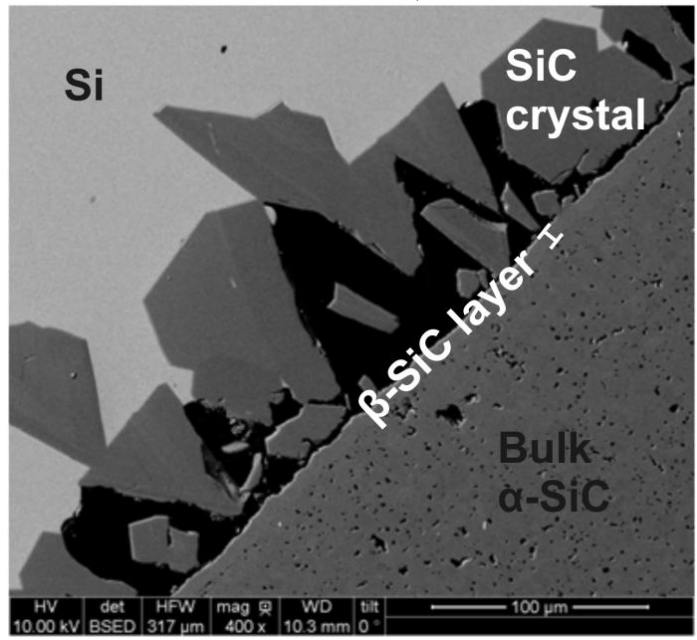

c)

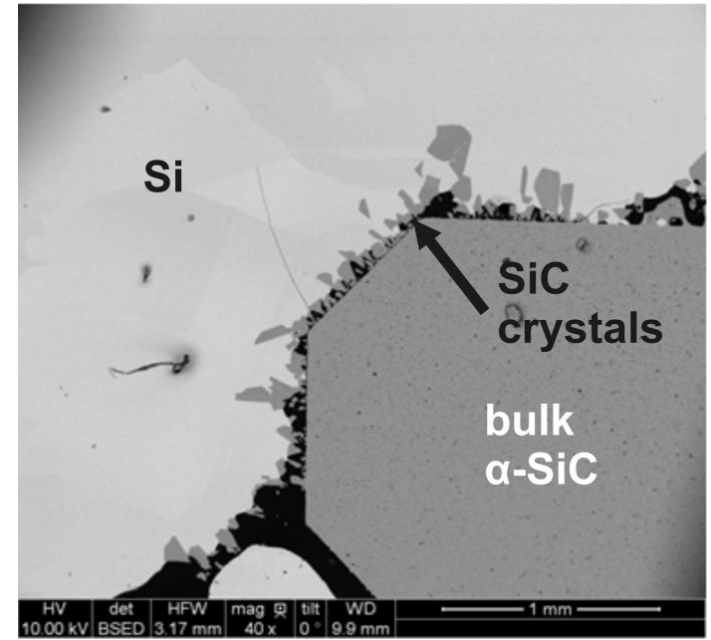

b)

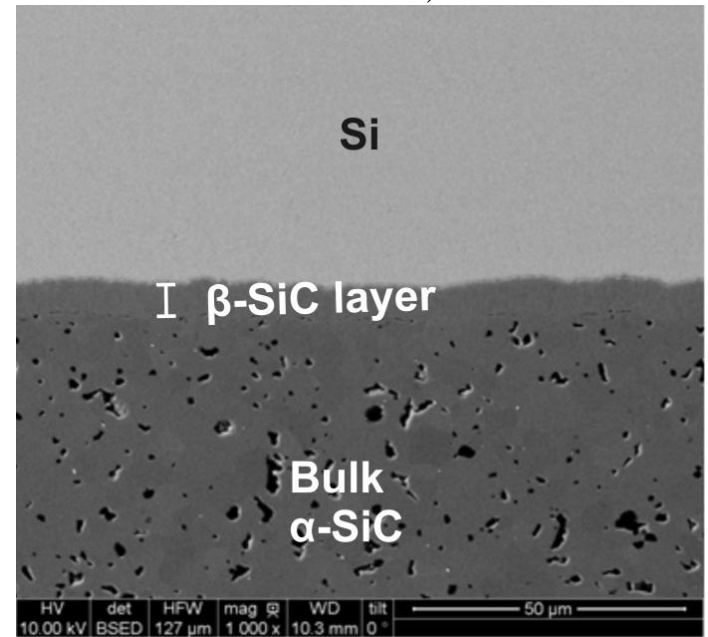

d)

Figure 8. Backscattered electrons images of the $\mathrm{SiC}$ pellet in silicon after $1450^{\circ} \mathrm{C}$ for $4 \mathrm{~h}$ : a) at the bottom of the $\mathrm{SiC}$ pellet, b) overall view of the sample,

c) at the interface $\mathrm{SiC} / \mathrm{Si}$ on the left side, d) at the interface $\mathrm{SiC} / \mathrm{Si}$ on the upper right side. 


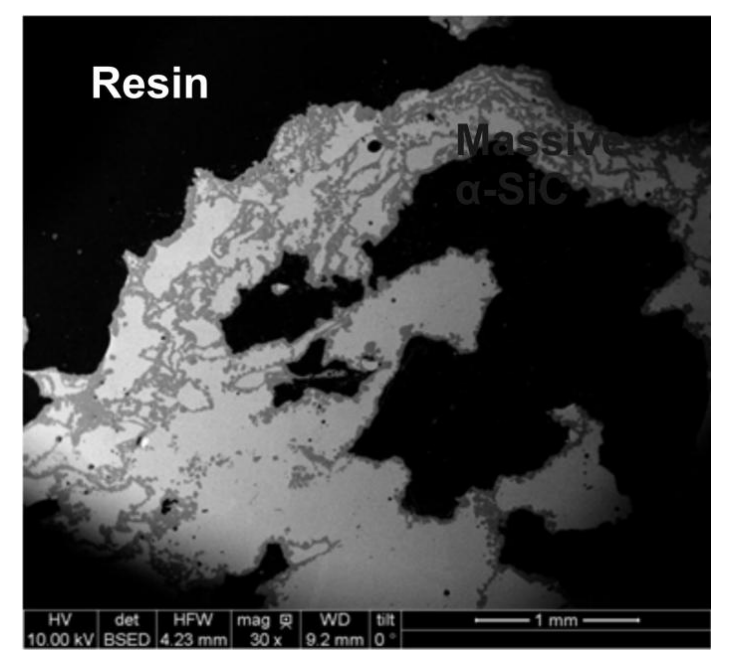

a)

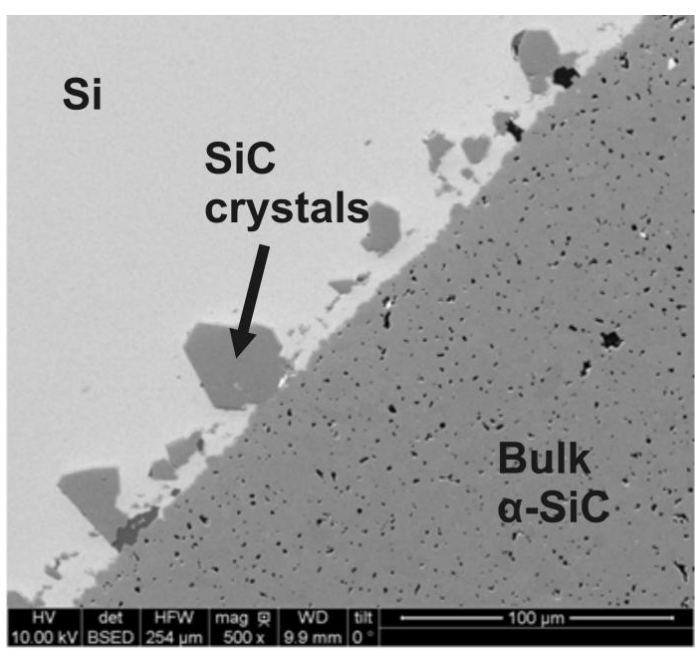

c)

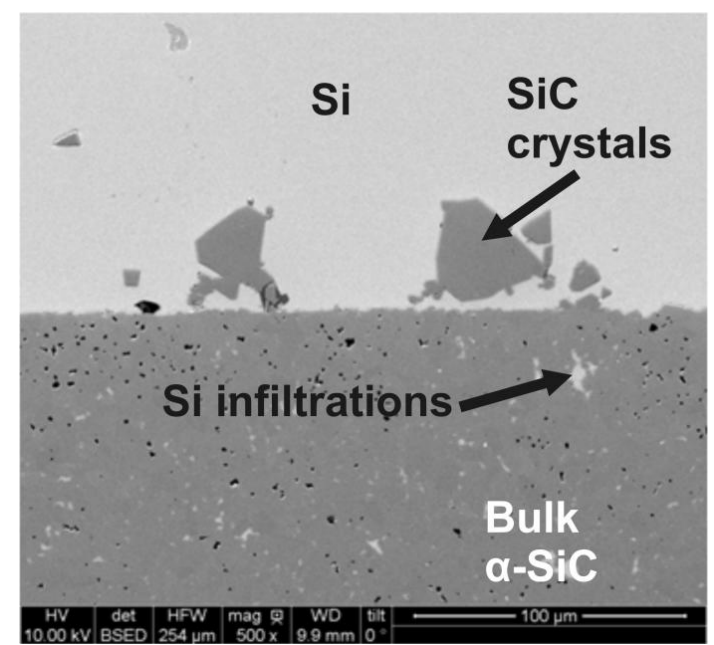

b)

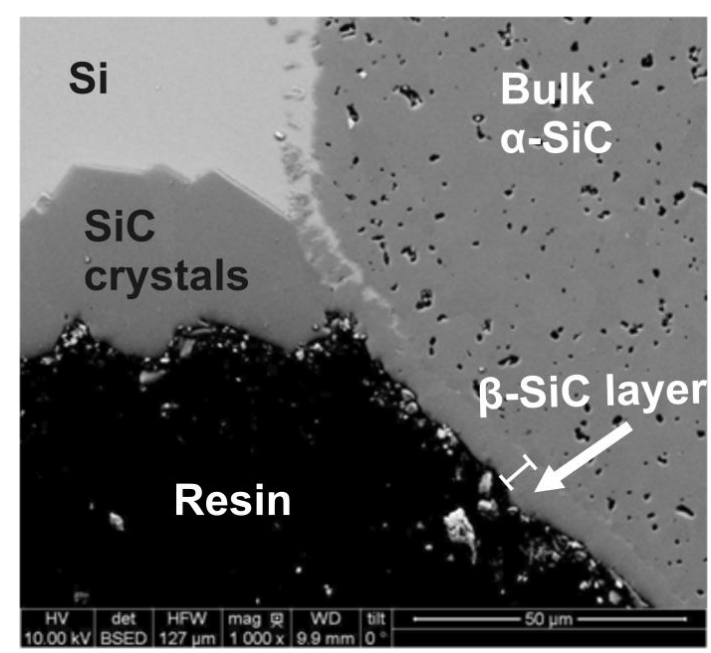

d)

Figure 9. Backscattered electrons images of the $\mathrm{SiC}$ pellet in silicon after $1600^{\circ} \mathrm{C}$ for $4 \mathrm{~h}$ :

a) at the top of the Si melt, b) at the interface $\mathrm{SiC} / \mathrm{Si}$ on the upper part,

c) at the interface $\mathrm{SiC} / \mathrm{Si}$ on the left side, d) at the interface $\mathrm{SiC} / \mathrm{Si}$ on the bottom.

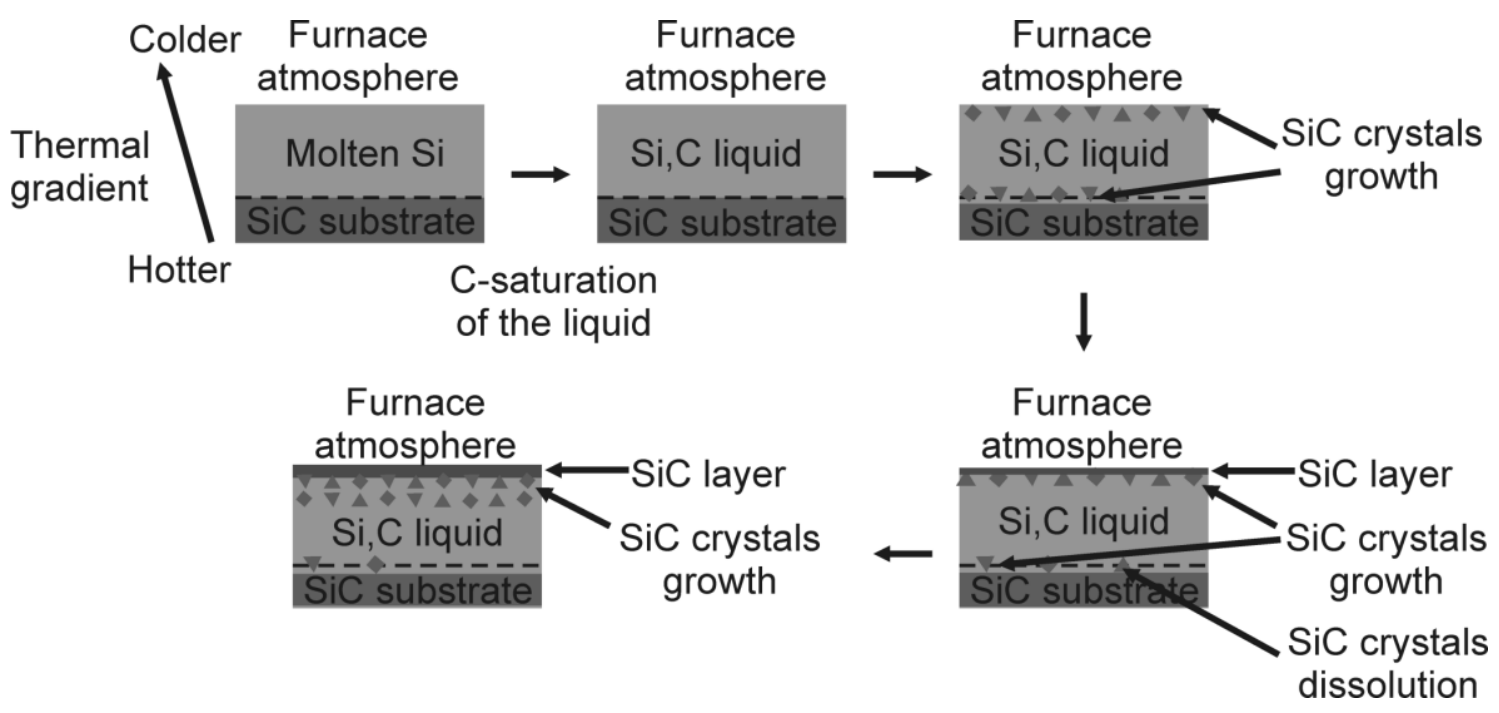

Figure 10. The stages of the interaction between dense $\mathrm{SiC}$ and molten $\mathrm{Si}$.

In the present case, the atmosphere of the furnace is a source of carbon. 